\title{
A "MENTALIDADE ALARGADA" E OS MIGRANTES: REFLEXõES A PARTIR DO PENSAMENTO POLÍTICO DE ARENDT
}

\author{
THE "ENLARGED MENTALITY" AND THE MIGRANTS: REFLECTIONS BASED ON \\ THE ARENDT'S POLITICAL THOUGHT
}

\section{Eduardo Jose Bordignon Benedetti ${ }^{1}$ \\ Sônia Maria Schio²}

\begin{abstract}
RESUMO
No pensamento de Hannah Arendt (1906-1975), a imaginação é um requisito para a compreensão, sendo a experiência e o exemplo fundamentais para a percepção da alteridade. Arendt retoma a ficção da "mentalidade alargada", desenvolvida incialmente por Kant no âmbito da Estética, de maneira que o ato de "colocar-se no lugar do outro", mesmo que mentalmente, torna-se um exercício necessário para a capacidade judicante porque permite a representação de todos os juízos possíveis para determinada situação. Assim, a hipótese a ser desenvolvida relaciona estética e política a fim de refletir acerca dos movimentos migratórios da atualidade - assumindo que eles contribuem para a difusão de normas cosmopolitas (como as de Direitos Humanos, por exemplo). Nesse sentido, para que os Direitos Humanos sejam efetivos é necessário o respeito às diferenças culturais dos povos que habitam o Planeta, sendo imprescindível a adoção de uma perspectiva baseada na condição humana da pluralidade que possibilita a manifestação da singularidade.
\end{abstract}

PALAVRAS-CHAVE: Arendt; Política; Mentalidade alargada; Migrações.

\begin{abstract}
In the Hannah Arendt (1906-1975) political thought the experience and the example are fundamental for the perception of alterity. Thus, the comprehension requires the imagination. Arendt retaken the "enlarged mentality" (or "broadened way of thinking", developed initially by Kant in his considerations about Aesthetics), so the act of putting yourself in another's people place, even mentally, becomes a necessary exercise for the judgment capacity. The paper aims to relate

\footnotetext{
${ }^{1}$ Bacharel em Direito e Mestre em Filosofia pela Universidade Federal de Pelotas (UFPel), Pelotas, Rio Grande do Sul, Brasil. Membro do Grupo de Estudos Hannah Arendt, também na UFPel. E-mail: eduardoj.benedetti@gmail.com

2 Professora Associada da Universidade Federal de Pelotas (UFPel), Pelotas, Rio Grande do Sul, Brasil. Doutora em Filosofia pela Universidade Federal do Rio Grande do Sul (UFRGS), Porto Alegre, Rio Grande do Sul, Brasil. Coordenadora do Grupo de Estudos Hannah Arendt (GEHAR/UFPel). E-mail: soniaschio@hotmail.com.
} 
BENEDETTI, Eduardo Jose Bordignon; SCHIO, Sônia Maria. A "mentalidade alargada" e os migrantes: reflexões a partir do pensamento político de Arendt. Revista Eletrônica Direito e Política, Programa de Pós-Graduação Stricto Sensu em Ciência Jurídica da UNIVALI, Itajaí, v.14, n.2, 20 quadrimestre de 2019. Disponível em: www.univali.br/direitoepolitica - ISSN 1980-7791

aesthetics and politics to reflect about the migratory movements from a cosmopolitan perspective (analyzing mainly the Human Rights topic). In this sense, the development of the Human Rights requires the respect for cultural differences, based on the human condition of plurality (condition that allows man's uniqueness as an individual agent to become manifest).

KEYWORDS: Arendt; politics; enlarged mentality; migrations

\section{INTRODUÇÃO}

A fim de traçar um panorama acerca da efetividade dos Direitos Humanos na atualidade, Benhabib ${ }^{3}$ constatou a persistência de um paradoxo em relação à disseminação de normas cosmopolitas (e o desenvolvimento de um regime internacional dos Direitos Humano) e sua extensão àqueles que não estão contemplados em um conceito de cidadania vinculado à nacionalidade.

Por seu turno, Hannah Arendt (1906-1975), em sua leitura do pensamento kantiano, retoma a "mentalidade alargada", de maneira que o ato de colocar-se no lugar do outro, mesmo que mentalmente, torna-se um exercício necessário para a capacidade de julgar porque permite a representação dos juízos políticos possíveis, um por vez, para determinada situação, sendo um ensaio para a ação política.

O juízo seria o tema do terceiro volume de $A$ Vida do Espírito, cujas primeiras linhas foram escritas por Arendt poucos dias antes de seu falecimento. Segundo Glenn Gray4, amigo pessoal de Arendt, ela considerava ser essa a saída "do impasse ao qual pareciam conduzi-la suas reflexões sobre a vontade". Encontramse referências esparsas sobre a questão do Julgar em toda a obra de Arendt, sendo que, especialmente em A Crise da Cultura (ensaio de 1972, em que discute o julgar em referência à phronesis de Aristóteles), e nas Conferências - reunidas em Lições sobre a Filosofia Política de Kant- pronunciadas em 1970 na New School for Social

\footnotetext{
${ }^{3}$ BENHABIB, Seyla. O declínio da soberania ou a emergência de normas cosmopolitas? Repensando a cidadania em tempos voláteis. Tradução de João Carlos Bassani e Johanna Clarissa Beckert. Civitas. Porto Alegre, volume 12, número 1, p. 20-46, 2012.

4 Conforme cita DENAMAY, Sylvie Courtine. Hannah Arendt. Tradução de Ludovina Figueiredo. Lisboa: Piaget, 1994, p.404.
} 
BENEDETTI, Eduardo Jose Bordignon; SCHIO, Sônia Maria. A "mentalidade alargada" e os migrantes: reflexões a partir do pensamento político de Arendt. Revista Eletrônica Direito e Política, Programa de Pós-Graduação Stricto Sensu em Ciência Jurídica da UNIVALI, Itajaí, v.14, n.2, 20 quadrimestre de 2019. Disponível em: www.univali.br/direitoepolitica - ISSN 1980-7791

Research, o julgar é desenvolvido por Ela como uma atividade autônoma do espírito.

A partir da leitura política do pensamento estético de Kant, no pensamento arendtiano a faculdade de julgar também se relaciona ao intuito de compreender os eventos políticos para além da cientificidade (relações de causa e efeito) ou das explicações postas no cotidiano. Nesse sentido, a hipótese a ser desenvolvida neste trabalho relaciona a mentalidade alargada (abordada por Kant no âmbito da estética e retomada por Arendt em uma leitura política) com o paradoxo constatado por Benhabib, que, por sua vez, é também uma leitora de Arendt. A partir disso, demonstra-se que os movimentos migratórios da atualidade, apesar dos procedimentos sumários de exclusão e de detenção de imigrantes praticados, contribuem para a difusão de normas cosmopolitas (como as de Direitos Humanos, por exemplo). Dessa forma, a investigação em curso situa-se necessariamente "nas fronteiras da política e da filosofia, na investigação da dimensão política dos conceitos filosóficos e das implicações filosóficas das experiências políticas cotidianas" ${ }^{\prime \prime}$, a fim de que o olhar para o futuro porte a esperança de um cosmopolitismo renovado.

\section{A MENTALIDADE ALARGADA: A LEITURA ARENDTIANA DE KANT}

Arendt apropriou-se de maneira peculiar da Crítica da Faculdade do Juízo $(1790)^{6}$ de Kant, desenvolvendo uma leitura política desta faculdade. Considerando esse caráter singular, acrescido ao fato de que a terceira parte da obra A vida do Espírito, que trataria do Juízo restou inconclusa, analisar essa apropriação é uma tarefa complexa. Todavia, para desenvolver as hipóteses dessa investigação, é central a leitura de Kant proposta por Arendt, especificamente no âmbito da estética:

\footnotetext{
${ }^{5}$ DUARTE, André. A dimensão política da filosofia kantiana segundo Hannah Arendt. In: ARENDT, Hannah; BEINER, Ronald (org). Lições sobre a Filosofia Política de Kant. Rio de Janeiro: Relume Dumará, 1994, p.165.

${ }^{6}$ Nas próximas menções o livro será referido pela abreviação, $\mathrm{KU}$, em referência ao título original em alemão, Kritik der Urteilskraft.
} 
BENEDETTI, Eduardo Jose Bordignon; SCHIO, Sônia Maria. A "mentalidade alargada" e os migrantes: reflexões a partir do pensamento político de Arendt. Revista Eletrônica Direito e Política, Programa de Pós-Graduação Stricto Sensu em Ciência Jurídica da UNIVALI, Itajaí, v.14, n.2, 20 quadrimestre de 2019. Disponível em: www.univali.br/direitoepolitica - ISSN 1980-7791

Kant insistiu, contudo, na Crítica do Juízo,, em um modo diverso de pensamento, ao qual não bastaria estar em concórdia com o próprio eu, e que consistia em ser capaz de "pensar no lugar de todas as demais pessoas" e ao qual denominou uma "mentalidade alargada"7

Em outro momento, Arendt afirma que uma chave para a leitura da primeira parte da KU seria o fato de que "companhia é indispensável para o pensador"8. Assim, ao invés de tratar de maneira exaustiva ou fornecer indicações interpretativas acerca da faculdade de Julgar, as sessões abaixo (1.1 e 1.2) são dedicadas a analisar o estatuto da apropriação arenditana do juízo estético de Kant, discutindo essa faculdade no que tange a importância política do "pensar no lugar dos outros".

\subsection{Da Faculdade do Juízo (Kant) a Vida do Espírito (Arendt)}

A KU é a última parte do "sistema crítico" de Kant, na qual o Filósofo se detém aos juízos que estão ligados a um sentimento de prazer ou desprazer, não contemplados em suas críticas anteriores (a Crítica a Razão Pura trata do conhecimento e a Crítica da Razão Prática, da moralidade). Na Introdução desta obra, Kant afirma que

A faculdade do juízo em geral é a faculdade de pensar o particular como contido sob o universal. No caso de este (a regra, o princípio, a lei) ser dado, a faculdade do juízo, que nele subsume o particular, é determinante (o mesmo acontece se ela, enquanto faculdade transcendental, indica a priori as condições de acordo com as quais apenas naquele universal é possível subsumir). Porém, se só o particular for dado, para o qual ela deve encontrar o universal, então a faculdade do juízo é simplesmente reflexiva?.

Baseando-se na Terceira Crítica, pode-se definir o Juízo, de maneira geral, como a faculdade de pensar o particular contido no universal. Segundo Kant, cada umas das três faculdades superiores do conhecimento (entendimento, razão e faculdade

\footnotetext{
7 ARENDT, Hannah. Lições sobre a filosofia política de Kant. 2.ed. Tradução de André Duarte. Rio de Janeiro: Relume Dumará, 1994, p.274.

8 ARENDT, Hannah. Lições sobre a filosofia política de Kant. p.15

9 KANT, Immanuel. Crítica da Faculdade do Juízo. 3.ed. Tradução de Valério Rohden e António Marques. Rio de Janeiro: Forense Universitária, 2008, XXVI, p. 23.
} 
BENEDETTI, Eduardo Jose Bordignon; SCHIO, Sônia Maria. A "mentalidade alargada" e os migrantes: reflexões a partir do pensamento político de Arendt. Revista Eletrônica Direito e Política, Programa de Pós-Graduação Stricto Sensu em Ciência Jurídica da UNIVALI, Itajaí, v.14, n.2, 20 quadrimestre de 2019. Disponível em: www.univali.br/direitoepolitica - ISSN 1980-7791

do juízo), possuem "legislação própria". Por sua vez, a faculdade do juízo corresponde também a uma "a faculdade de julgar reflexiva e que se exerce a partir do particular de maneira quase indutiva e contudo a priori"10;

Por seu turno, o juízo reflexionante (ou reflexivo) pode ser estético ou teleológico (o primeiro relativo aos sentidos, e o segundo, à finalidade). Na primeira parte da KU (Analítica do Belo), Kant trata de um tipo específico do juízo estético, que é o juízo de gosto. Para ele o gosto é "a faculdade de ajuizamento de um objeto ou de um modo de representação mediante uma complacência [prazer (Lust)] ou uma descomplacência [desprazer (Unlust)] independente de todo interesse"11. O juízo de gosto é contemplativo e não depende de quaisquer interesses ou finalidade. No gosto ocorre o "aprazer" e o "não aprazer"; isto é, aquilo que aproxima ou aquilo que repulsa, afasta. Segundo Kant, o gosto é uma questão de autonomia: "De cada juízo que deve provar o gosto do sujeito, é reclamado que o sujeito deva julgar por si, sem ter necessidade de, pela experiência, andar às apalpadas entre os juízos de outros"12. De certa forma, o sujeito sente a si mesmo quando é afetado por uma situação que Ihe apraz ou não lhe apraz: isso gera um sentimento de prazer ou de desprazer, que, por seu turno, relaciona-se com uma faculdade de distinção e julgamento. O gosto não ocorre no sujeito ou no objeto, mas sim no sujeito quando em relação com o objeto.

Por sua vez, Arendt apropriou-se das elaborações de Kant, abordando juízo como uma atividade autônoma do espírito, junto com o pensar e o querer. Acerca disso, Schio afirma que "Arendt relaciona o estético e o político, baseando-se em Kant, porque a política carece dos parâmetros que a estética lhe fornece; o prazer desinteressado, livre e comunicável; o preenchimento de lacunas sociais por meio da mentalidade alargada"13. Na leitura arendtiana, a KU não se limita à faculdade do julgar, retomando questões que já estavam presentes na "fase pré-crítica" do

\footnotetext{
10 ROHDEN, Valério. Juízo e reflexão desde de um ponto de vista prático. o que nos faz pensar, Rio de Janeiro, volume 1, número 09, p. 41, 1995.

11 KANT, Immanuel. Crítica da Faculdade do Juízo. $\S 55$, p.182

12 KANT, Immanuel. Crítica da Faculdade do Juízo. $§ 56$, p. 183

13 SCHIO, Sônia Maria. Hannah Arendt: a estética e a política (do juízo estético ao juízo político). Tese de doutorado, Porto Alegre: Universidade Federal do Rio Grande do Sul, 2008. p.187.
} 
BENEDETTI, Eduardo Jose Bordignon; SCHIO, Sônia Maria. A "mentalidade alargada" e os migrantes: reflexões a partir do pensamento político de Arendt. Revista Eletrônica Direito e Política, Programa de Pós-Graduação Stricto Sensu em Ciência Jurídica da UNIVALI, Itajaí, v.14, n.2, 20 quadrimestre de 2019. Disponível em: www.univali.br/direitoepolitica - ISSN 1980-7791

pensamento de Kant, como a perspectiva do homem enquanto ser que convive em um espaço de pluralidade. Dessa forma,

os tópicos da Crítica do Juízo - o particular, como um fato da natureza ou um evento da história; a faculdade do juízo, como faculdade do espírito humano para lidar com o particular, a sociabilidade dos homens como condição de funcionamento daquela faculdade, ou seja, o vislumbre de que os homens são dependentes de seus companheiros não apenas porque têm um corpo e necessidades físicas, mas precisamente por suas faculdades do espírito - estes tópicos, todos de eminente significação política, isto é, importantes para a política, já eram preocupações de Kant muito antes que voltasse a elas $[\ldots]$, concluindo o ofício crítico ${ }^{14}$.

No pensamento arendtiano, o juízo é uma das atividades espirituais, junto com o pensamento e a vontade. Em termos gerais, o pensamento é o responsável por atualizar os dados advindos do mundo exterior; isto é, ele captura os dados do mundo exterior para a busca do significado deles.

Segundo Arendt, "o pensamento está sempre fora de ordem, interrompendo todas as atividades ordinárias e sendo por elas interrompido"15. A partir do convívio entre os iguais, e das percepções do senso comum, o pensamento demanda a introspecção; isto é, a retirada do "mundo das aparências" para um diálogo entre o sujeito e ele mesmo. É essencial ter em consideração os outros seres humanos, a vida humana em comum. Trata-se aqui da "alteridade", do outro que é conhecido, com quem o agente se relaciona por meio do discurso e da performance pública. Para Arendt a alteridade é um aspecto importante da pluralidade porque "faz com que possamos definir apenas pela distinção, que sejamos incapazes de dizer o que algo é sem distingui-lo de alguma outra coisa. Ademais, partilhamos com todo organismo vivo aquele tipo de traços distintivos que o torna um ente individual"16.

\footnotetext{
${ }^{14}$ ARENDT, Hannah. Lições sobre a filosofia política de Kant.p.18.

15 ARENDT, Hannah. A Vida do Espírito: o pensar, o querer, o julgar. Traduçaõ de Antonio Abranches, Augusto R de Almeida e Helena Martins.Rio de Janeiro: Relume Dumará, 2002.P.149.

16 ARENDT, Hannah. Trabalho, obra, ação. Cadernos de Ética e Filosofia Política. Tradução de Adriano Correia. Revisão de Theresa Calvet de Magalhães. São Paulo, volume 7, número 2, 2005, p.190.
} 
BENEDETTI, Eduardo Jose Bordignon; SCHIO, Sônia Maria. A "mentalidade alargada" e os migrantes: reflexões a partir do pensamento político de Arendt. Revista Eletrônica Direito e Política, Programa de Pós-Graduação Stricto Sensu em Ciência Jurídica da UNIVALI, Itajaí, v.14, n.2, 20 quadrimestre de 2019. Disponível em: www.univali.br/direitoepolitica - ISSN 1980-7791

Por sua vez, o pensamento, em sua atividade, obedece ao princípio da nãocontradição, porém, ao desensorializar os dados, permite organizá-los de outra forma, buscar o que eles significam para aquela situação específica. Todavia, em um estado de solidão (como o vivenciado nos Regimes Totalitários), é obstaculizado o convívio entre iguais. Nesse caso, caberá à imaginação tornar presente o ausente ${ }^{17}$. Acerca disso, importante notar que, para Arendt, "isolamento e solidão não são a mesma coisa"18, o isolamento refere-se a destruição da esfera política, de modo que os indivíduos estejam sem contato com seus iguais. Estar solitário é sentir-se "completamente abandonado por toda companhia humana"19, embora sem estar isolado.

Por sua vez, a imaginação, recorrendo a uma metáfora, é como o exercício infantil de criar um personagem imaginário que possibilita ao agente a relativização de seus pontos de vista. Logo, imaginar é uma atividade necessária para manter o humano, pois permite ampliar o diálogo interno e elaborar modelos para deliberar, quanto aos seus possíveis resultados no mundo externo para depois escolher e agir. Ela estabelece as relações e as funções dos fatos passados, propiciando que o vivido não fique disperso ${ }^{20}$.

A seguir, o que foi pensando (em um diálogo do sujeito consigo mesmo), será comparado e aplicado ao particular em questão. Esse segundo momento é o julgar que será procedido pela vontade. Acerca do juízo, Arendt, ao comentar a afirmativa de Kant de que o juízo é a "faculdade de pensar o particular", ressalta que nessa definição está implícita uma combinação "misteriosa" entre o geral e o particular porque, o ato de pensar, por si mesmo, "significa generalizar"21. Essa questão é central no caso dos juízos reflexivos, em que há um particular para o qual o universal não está dado; ou seja, não está presente e passível de utilização.

17 Conforme SCHIO, Sônia Maria. Hannah Arendt: a estética e a política (do juízo estético ao juízo político). p.16.

18 ARENDT, Hannah. As Origens do Totalitarismo. Tradução de Roberto Raposo. São Paulo: Companhia das Letras, 1989, p.527.

${ }^{19}$ ARENDT, Hannah. As Origens do Totalitarismo. p.527

${ }^{20}$ Acerca da relação entre imaginação e juízo em Arendt, ver SCHIO, Sônia Maria. Hannah Arendt: imaginação e juízo político. In: SIVIERO, Iltomar; ROSIN, Nilva (Org.). Hannah Arendt: diversas leituras. Passo Fundo: IFIBE, 2010, p. 45-60.

${ }^{21}$ ARENDT, Hannah. Lições sobre a filosofia política de Kant. p.76. 
BENEDETTI, Eduardo Jose Bordignon; SCHIO, Sônia Maria. A "mentalidade alargada" e os migrantes: reflexões a partir do pensamento político de Arendt. Revista Eletrônica Direito e Política, Programa de Pós-Graduação Stricto Sensu em Ciência Jurídica da UNIVALI, Itajaí, v.14, n.2, $2^{\circ}$ quadrimestre de 2019. Disponível em: www.univali.br/direitoepolitica - ISSN 1980-7791

Além de conjugar particular e o universal, o juízo também une mas também o mundo interno e o externo, na medida que, depois do julgamento, a vontade envia (ou não) o impulso para a ação.

\subsection{Juízo como atividade política}

No pensamento arendiano, o juízo possui relevância política, posto que ocorre somente na presença dos outros, seja de maneira real ou virtual (representativa). Sendo assim, para compreender é necessário também perceber a historicidade que envolve o mundo comum, uma vez que ele perdura para além do sujeito. Então, a imaginação acaba sendo uma instância mediadora porque possibilita certa distância entre o sujeito e o objeto para que este possa ser averiguado com neutralidade.

Segundo Arendt, a imaginação "nos permite ver as coisas em suas perspectivas próprias; só ela coloca a certa distância do que está próximo demais para que possamos ver e compreender sem tendências ou preconceitos"'22. Em $A$ condição Humana (1958), ao tratar da fundação, Arendt afirma que a imaginação pode inclusive "devassar um passado e um evento que a memória não podia alcançar"23. A imaginação relaciona-se também com a capacidade de desenvolver narrativas para além de clichês e das noções "automatizadas" presentes no cotidiano.

Dessa forma, a imaginação permite que os outros seres humanos sejam presentificados "virtualmente"; ou seja, possibilita imaginar opiniões e argumentos, em uma espécie de "visita à perspectiva dos outros". Nesse sentido, é possível "transpor-se para o lugar dos outros" porque a faculdade da imaginação permite aquilo que Kant denominou de "pensar alargado", conforme exposto no $\S 40$ da KU. Nesse parágrafo, Kant apresenta as máximas do entendimento humano, as quais auxiliam no ajuizamento; a saber, o pensar por si (pensar livre de preconceito), o pensar no lugar do outro (pensar alargado) e o pensar sempre

\footnotetext{
22 ARENDT, Hannah. A dignidade da política. Tradução de Helena Martins. Rio de Janeiro: Relume Dumará, 1993, p.53.

23 ARENDT, Hannah. A condição humana. Tradução de Roberto Raposo. Rio de Janeiro: Forense Universitária, 2010, p.167.
} 
BENEDETTI, Eduardo Jose Bordignon; SCHIO, Sônia Maria. A "mentalidade alargada" e os migrantes: reflexões a partir do pensamento político de Arendt. Revista Eletrônica Direito e Política, Programa de Pós-Graduação Stricto Sensu em Ciência Jurídica da UNIVALI, Itajaí, v.14, n.2, 20 quadrimestre de 2019. Disponível em: www.univali.br/direitoepolitica - ISSN 1980-7791

em acordo consigo próprio (pensar consequente). O pensar alargado, enquanto um procedimento, é dito "alargado" porque opõe-se a um pensar "estreito", limitado: é uma maneira de pensar para além da subjetividade privada do sujeito, considerando um ponto de vista universal.

Na Décima Segunda Lição de Lições sobre a Filosofia Política de Kant" (obra póstuma, que reúne notas de um curso proferido por Arendt em 1970), Arendt apresenta sua perspectiva acerca do sensus communis, teorizado por Kant, e estabelece uma diferenciação. Ela esclarece que o uso do termo em latim denota a intenção de Kant de diferenciar o que é o conhecimento básico (ou do senso comum) deste "sentido extra", que é especificamente humano porque depende da comunicabilidade ${ }^{24}$,

O sensus communis é uma "capacidade extra do espírito que nos ajusta a vida em comunidade"25, aparecendo ao indivíduo pela sensação de prazer ou de desprazer ("isso me agrada ou isso me desagrada"). Para tanto, é necessária a atividade judicante, um "jogo livre" entre o entendimento e a imaginação. Essa atribuição de significado não se refere apenas à sensação imediata, pois ocorre na medida em que o sujeito relaciona esse prazer/desprazer com esse "sentido comum". Segundo Kant:

Por sensus communis, porém, se tem que entender a ideia de um sentido comunitário, isto é, de uma faculdade de ajuizamento que em sua reflexão toma em consideração em pensamento (a priori) o modo de representação de qualquer outro, como que para ater o seu juízo a inteira razão humana e assim escapar a ilusão que, a partir de condições privadas subjetivas - as quais facilmente poderiam ser tomadas por objetivas - teria influencia prejudicial sobre o juízo ${ }^{26}$.

A mentalidade alargada, por seu turno, é como se fosse uma "ferramenta" do espírito, que potencializa as suas atividades. Dessa forma, o sensus communis é ativado, não sendo necessária a mediação de conceitos, ou mesmo o recurso há alguma espécie de normatividade. Pelo contrário, basta esse sentimento de

\footnotetext{
${ }^{24}$ Conforme ARENDT, Hannah. A Vida do Espírito: o pensar, o querer, o julgar. p.378.

25 ARENDT, Hannah. Lições sobre a filosofia política de Kant. p.71.

26 KANT, Immanuel. Crítica da Faculdade do Juízo. § 40, p.39, Grifos do autor.
} 
BENEDETTI, Eduardo Jose Bordignon; SCHIO, Sônia Maria. A "mentalidade alargada" e os migrantes: reflexões a partir do pensamento político de Arendt. Revista Eletrônica Direito e Política, Programa de Pós-Graduação Stricto Sensu em Ciência Jurídica da UNIVALI, Itajaí, v.14, n.2, 20 quadrimestre de 2019. Disponível em: www.univali.br/direitoepolitica - ISSN 1980-7791

"satisfação desinteressada", porque refere-se a sensibilidade, é anterior a considerações éticas e morais. Acerca disso, Arendt enfatiza, baseada em Kant, que a tarefa de colocar-se no lugar do outro de maneira ficcional é possível pela "ideia de um sentido comum a todos, isto é, de uma faculdade do juízo que, em sua reflexão, leva em conta (a priori) o modo de representação de todos os outros homens em pensamento, para, de certo modo, comparar seu juízo com a razão coletiva da humanidade"27. Em relação ao juízo, o acordo consigo mesmo não basta; é necessário colocar-se no lugar das outras pessoas, uma a uma, formando uma comunidade de opiniões possíveis.

Em relação a Kant, considera-se que a exposição do sensus communis, no §40, demonstra que a mentalidade alargada envolve a participação potencial de outros membros da comunidade e, nesse sentido, pressupõe a intersubjetividade ${ }^{28}$. Ao invés de apresentar a estética como uma alternativa individualista à universalidade da teoria moral de Kant, Arendt ressalta a capacidade de sentir prazer ou desprazer (Lust e Unlust) com aquilo que interessa a comunidade. Ela apresenta, então, o gosto (que, para Kant, é o tipo especifico de juízo estético que trata do prazer/desprazer) como um "senso de comunidade", que afeta o ator tal qual uma "sensação"29. Sendo assim,

Arendt relaciona o estético e o político, baseando-se em Kant, porque a política carece dos parâmetros que a estética lhe fornece: o prazer desinteressado, livre e comunicável; o preenchimento de lacunas sociais por meio da "mentalidade alargada". Não se pode, então, tratar do político sem passar pelo estético porque o juízo estético, em suma, amplia a experiência humana, expandindo as vivências emocionais e morais; extrapolando a cultura imposta; permitindo a ocorrência do novo; expondo paradoxos, enfim, levando ao pensar livre, e com isso, mantendo o humano ${ }^{30}$.

\footnotetext{
27 ARENDT, Hannah. A Vida do Espírito: o pensar, o querer, o julgar. p.379.

28 SCHIO, Sônia Maria. Hannah Arendt: a estética e a política (do juízo estético ao juízo político). p.110.

${ }^{29}$ ARENDT, Hannah. A Vida do Espírito: o pensar, o querer, o julgar, p.379.

30 SCHIO, Sônia Maria. Hannah Arendt: a estética e a política (do juízo estético ao juízo político), p.187-188.
} 
BENEDETTI, Eduardo Jose Bordignon; SCHIO, Sônia Maria. A "mentalidade alargada" e os migrantes: reflexões a partir do pensamento político de Arendt. Revista Eletrônica Direito e Política, Programa de Pós-Graduação Stricto Sensu em Ciência Jurídica da UNIVALI, Itajaí, v.14, n.2, 20 quadrimestre de 2019. Disponível em: www.univali.br/direitoepolitica - ISSN 1980-7791

\begin{abstract}
Segundo Benhabib ${ }^{31}$, a análise arendtiana do pensamento alargado, ao invés de afirmar a distinção kantiana entre as faculdades de distinguir o certo do errado (razão prática) e o juízo (que trataria de distinguir o belo do repugnante), enfatiza que há em Kant o modelo para o tipo de validade intersubjetiva que se procura alcançar na esfera pública.
\end{abstract}

Considerando que a filosofia de Kant influenciou o pensamento político arendtiano, é necessário atentar para a possibilidade de compatibilização entre o universalismo kantiano e o conceito de ação em Arendt, que é uma noção relativa a um contexto determinado, das teias de relação estabelecidas. Nesse ponto, "a grande dificuldade do juízo, aponta Hannah Arendt, é a de ser a faculdade de pensar o particular [porque] pensar significa generalizar; daí o mistério da combinação do geral com o particular. Se o geral fosse dado, o juízo limitar-se-ia a enquadrar o particular na norma universal"32. A mentalidade alargada em Kant considera o ponto de vista dos outros, não pela empatia, mas pela abstração.

Segundo a leitura sugerida por Benhabib (o que também relaciona-se com outros argumentos desenvolvidos pela autora, como a existência de uma conexão entre moral e política - o que é afastado por Arendt - e a filiação a uma Ética do Discurso, o denominado de universalismo interativo), em Arendt, a comunicabilidade universal, que é a base de validade do juízo reflexivo (Kant), é interpretada a partir do pensamento alargado. Assim, "quanto mais se pensa na perspectiva dos outros, mais podemos vivificar para nós mesmos as narrativas" ${ }^{\prime 33}$. A mentalidade alargada é um "exercício" para o pensamento, que estabelece uma complementaridade entre $o$ ator-espectador ${ }^{34}$ e a alteridade.

31 BENHABIB, Seyla. The Reluctant Modernity of Hannah Arendt. Oxford: Rowman \& Littlefield, 1996, p. 39.

32 LAFER, Celso. Hannah Arendt: pensamento, persuasão, poder. p.126.

33 BENHABIB, Seyla. The Reluctant Modernity of Hannah Arendt. p.43.

34 Arendt afirma que: "a pensar que, para julgar um espetáculo, devemos ter antes o espetáculo que o espectador é secundário em relação ao ator; tendemos a esquecer que ninguém em sua plena razão apresentaria um espetáculo se não estivesse certo de ter espectadores para assistilo." Assim, ela questiona a afirmativa e que o espectador seria secundário ao ator. Em se tratando de política, todos os seres humanos são atores (quando aparecem para os outros) e espectadores (quando desvelam os sentidos do agir).

ARENDT, Hannah. A Vida do Espírito: o pensar, o querer, o julgar. p.62. 
BENEDETTI, Eduardo Jose Bordignon; SCHIO, Sônia Maria. A "mentalidade alargada" e os migrantes: reflexões a partir do pensamento político de Arendt. Revista Eletrônica Direito e Política, Programa de Pós-Graduação Stricto Sensu em Ciência Jurídica da UNIVALI, Itajaí, v.14, n.2, 20 quadrimestre de 2019. Disponível em: www.univali.br/direitoepolitica - ISSN 1980-7791

Essa "máxima do entendimento humano" (expressão de Kant), para Arendt, "não é, como o processo de pensamento do raciocínio puro, um diálogo de mim para comigo, porém se acha sempre e fundamentalmente, [...], em antecipada comunicação com o outros, com quem sei que devo ao final chegar a algum consenso" 35 , remetendo, portanto, a um universalismo que não ignore as questões contextuais - sobretudo em razão da espontaneidade da ação política.

A pluralidade, uma das condições (humanas) da ação e do discurso, relaciona-se tanto à espontaneidade dos atores quanto à multiplicidade de interpretações e de julgamentos possíveis. Ademais, refere-se também ao fato de que os sujeitos modificam a si mesmos no transcorrer da ação, na medida em tomam contato com uma multiplicidade de comunidades que "obedecem a diferentes leis, tendo diferentes hábitos e costumes, e acalentando diferentes memórias do passado, isto é, uma multiplicidade de tradições"36. O mundo aparece para os sujeitos sempre em dependência de "perspectivas particulares determinadas tanto pela posição no mundo quanto pelos órgãos específicos da percepção"37. A "sensação de realidade" que os sujeitos possuem, segundo Arendt, não é uma questão individual, sendo influenciada por:

a) os cinco sentidos, inteiramente distintos uns dos outros, [que] têm em comum o mesmo objeto; b) os membros da mesma espécie têm em comum o contexto que dota cada objeto singular de seu significado específico; c) e todos os outros seres sensorialmente dotados, embora percebam esse objeto a partir de perspectivas inteiramente distintas, estão de acordo acerca de sua identidade ${ }^{38}$.

A realidade, em relação ao aparecimento público, não é uma questão objetiva porque se trata de "sensações". Segundo Arendt, "nada do que é, à medida que aparece, existe no singular; tudo que é, é próprio para ser percebido por alguém" ${ }^{\prime 39}$. O pensar alargado faz parte do conjunto de formas pelas quais o mundo

\footnotetext{
35 ARENDT, Hannah. Lições sobre a filosofia política de Kant. Rio de Janeiro. p.274.

36 ARENDT, Hannah. A Vida do Espírito: o pensar, o querer, o julgar. p.337.

37 ARENDT, Hannah. A Vida do Espírito: o pensar, o querer, o julgar. p. 31.

38 ARENDT, Hannah. A Vida do Espírito: o pensar, o querer, o julgar. p.67.

39 ARENDT, Hannah. A Vida do Espírito: o pensar, o querer, o julgar. p.35
} 
BENEDETTI, Eduardo Jose Bordignon; SCHIO, Sônia Maria. A "mentalidade alargada" e os migrantes: reflexões a partir do pensamento político de Arendt. Revista Eletrônica Direito e Política, Programa de Pós-Graduação Stricto Sensu em Ciência Jurídica da UNIVALI, Itajaí, v.14, n.2, $2^{\circ}$ quadrimestre de 2019. Disponível em: www.univali.br/direitoepolitica - ISSN 1980-7791

aparece para os sujeitos, dependendo tanto do ponto de vista, quanto dos órgãos da percepção, sendo um processo sempre inconcluso.

\section{MIGRAÇÕES E CIDADANIA TRANSNACIONAL}

\subsection{O direito a ter direitos e os(as) migrantes na atualidade}

Ao tratar da questão dos apátridas, em As Origens do Totalitarismo (1951), Arendt admite que as causas para a existência desses indivíduos "sem lugar no mundo", são diversas, não podendo atribuir-se a um único fator nem à existência de uma "diversidade grupal de apátridas". O fim da Primeira Guerra Mundial (1914-1918), e a consequente derrocada dos grandes impérios multinacionais (Império AustroHúngaro, Czarista e Otomano) afirmou o sistema de Estados na Europa. Nesse contexto, questionou-se os limites do conceito de "Estado", sobretudo no que tange aos "problemas concretos de denotação do conceito de nação provenientes do surgimento das minorias e dos refugiados, que colocaram a hipótese da falta de coincidência entre o Estado e a nação"40.

Em princípio, a atribuição para supervisionar a efetividade das legislações de cada Estado acerca das minorias seria da "Sociedade das Nações" (criada em 1919). Entretanto, essa emergente ordem interestatal não suportou as tensões surgidas entre os direitos coletivos dessas minorais e os da nação em que se encontravam ${ }^{41}$. Os limites da proteção interestatal foram objeto da crítica de Arendt, principalmente em relação aos Direitos do Homem, que "mostraram-se inexequíveis - mesmo nos países cujas constituições se baseavam neles - sempre que surgiam pessoas que não eram cidadãos de algum Estado soberano"42. Os supostos "direitos do homem" demonstraram-se limitados aos "direitos do

\footnotetext{
40 LAFER, Celso. A reconstrução dos Direitos Humanos: um diálogo com o pensamento de Hannah Arendt. São Paulo: Companhia das Letras, 1988. p.141.

41 LAFER, Celso. A reconstrução dos Direitos Humanos: um diálogo com o pensamento de Hannah Arendt. p.142.

42 ARENDT, Hannah. As Origens do Totalitarismo. p.317.
} 
BENEDETTI, Eduardo Jose Bordignon; SCHIO, Sônia Maria. A "mentalidade alargada" e os migrantes: reflexões a partir do pensamento político de Arendt. Revista Eletrônica Direito e Política, Programa de Pós-Graduação Stricto Sensu em Ciência Jurídica da UNIVALI, Itajaí, v.14, n.2, 20 quadrimestre de 2019. Disponível em: www.univali.br/direitoepolitica - ISSN 1980-7791

cidadão"; isto é, sua efetividade está condicionada ao pertencimento a um Estado Nacional.

Com a emergência dos Totalitarismos, os atos de desnacionalização em massa praticados criaram uma situação ainda mais paradoxal. Os apátridas tornaram-se os verdadeiros "refugos da Terra" pela impossibilidade de enquadramento de sua situação nos institutos jurídicos existentes. Nesse caso, o direito de asilo territorial não era aplicável, por ser voltado ao indivíduo, condenado em seu país de origem pela prática de crime político. Por outro lado, institutos como a naturalização e a repatriação, encontravam limites em um cenário de crise econômica e de ascensão do nacionalismo.

Os apátridas (ou displaced persons) tornaram-se, então, "o refugo da terra, pois nem o país de origem nem qualquer outro os aceitavam, passando estes refugiados a dever suas vidas não ao Direito, mas à caridade. Daí a impossibilidade destes desprivilegiados recorrerem aos direitos humanos."43. Essa indefinição em relação aos apátridas demonstra ser possível tratar os seres humanos como se não fossem humanos. Segundo Arendt ${ }^{44}$ :

[...] quanto mais clara é a demonstração da sua incapacidade de tratar os apátridas como "pessoas legais", e quanto mais extenso é o domínio arbitrário do decreto policial, mais difícil é para os Estados resistir à tentação de privar todos os cidadãos da condição legal e dominá-los com uma polícia onipotente.

Longe de tratar-se de um problema do século $X X$, existem, segundo estimativas da ACNUR (Alto Comissariado das Nações Unidas para os Refugiados) ${ }^{45}$, cerca de 10 milhões de apátridas no mundo (ainda que os dados dos governos e comunicados ao ACNUR se limitem a 3,5 milhões de apátridas em 77 países), em adição a um universo de 68,5 milhões de pessoas que se deslocaram forçosamente por guerras e conflitos.

\footnotetext{
43 LAFER, Celso. A reconstrução dos Direitos Humanos: um diálogo com o pensamento de Hannah Arendt. p.143.

44 ARENDT, Hannah. As Origens do Totalitarismo. p.324.

45 Conforme informações disponíveis em: https://www.acnur.org/portugues/dados-sobre-refugio/ Acesso em 12.Mar.2019.
} 
BENEDETTI, Eduardo Jose Bordignon; SCHIO, Sônia Maria. A "mentalidade alargada" e os migrantes: reflexões a partir do pensamento político de Arendt. Revista Eletrônica Direito e Política, Programa de Pós-Graduação Stricto Sensu em Ciência Jurídica da UNIVALI, Itajaí, v.14, n.2, 20 quadrimestre de 2019. Disponível em: www.univali.br/direitoepolitica - ISSN 1980-7791

Por seu turno, o refúgio é considerado o grande "êxodo" do século XXI, posto que suas razões não estão mais restritas a expulsões e desnacionalizações, pois ocorrem principalmente em países que não conseguem tutelar e garantir direitos mínimos à população. Enfim, apátridas, refugiados, asilados, imigrantes ilegais, apesar de designarem situações juridicamente distintas, possuem uma semelhança entre si: vivendo de forma desprotegida, não têm sua existência garantida pelo "direito a ter direitos"46. Essas pessoas são, conforme constata Agamben, "um conceito limite que põe em crise radical as categorias fundamentais do Estado-nação, do nexo nascimento-nação" e que relegam o domínio da política ao debate "vida nua-existência política, zoé-bíos, exclusão-inclusão"47.

Em relação às migrações, apesar das particularidades das diversas crises que se enfrentam em distintas regiões do mundo, percebe-se que a maior parte das políticas adotadas não avançam no questionamento à constituição do Estado Moderno, que, desde o século XVI, baseia-se no domínio territorial, no controle administrativo, na consolidação de uma identidade cultural coletiva e na legitimidade política por mecanismos de representação ${ }^{48}$. Todavia, essa concepção não questiona os problemas advindos da rígida delimitação entre política externa e interna. Como exemplo, pode-se citar as políticas de estabelecimento de Campos para refugiados. Na Europa, os "campos de trânsito para o processamento de refugiados" (RPTCs), instituídos fora das fronteiras da União Europeia, [são utilizados] para capturar refugiados e imigrantes ilegais antes que eles cheguem em solo europeu"49.

Da mesma forma, na África tem-se o exemplo do campo de Refugiados Dadaab, no Quênia. Esse campo, que abriga, em sua maioria, refugiados Somalianos, é distante dos centros urbanos, não oferece condições de mobilidade, de acesso aos empregos e à geração de renda. Ademais, os habitantes do campo não pertencem

\footnotetext{
46 Para mais detalhes, ver AGAMBEN, Giorgio. Homo Sacer. O Poder Soberano e a Vida Nua I. Tradução de Henrique Burigo. Belo Horizonte: Editora UFMG, 2002.

47 AGAMBEN, Giorgio. Homo Sacer. O Poder Soberano e a Vida Nua I. p.140.

48 BENHABIB, Seyla. O declínio da soberania ou a emergência de normas cosmopolitas? Repensando a cidadania em tempos voláteis.p.21.

49 BENHABIB, Seyla. O declínio da soberania ou a emergência de normas cosmopolitas? Repensando a cidadania em tempos voláteis. p.22.
} 
BENEDETTI, Eduardo Jose Bordignon; SCHIO, Sônia Maria. A "mentalidade alargada" e os migrantes: reflexões a partir do pensamento político de Arendt. Revista Eletrônica Direito e Política, Programa de Pós-Graduação Stricto Sensu em Ciência Jurídica da UNIVALI, Itajaí, v.14, n.2, 20 quadrimestre de 2019. Disponível em: www.univali.br/direitoepolitica - ISSN 1980-7791

à jurisdição estatal, estando sob a guarda de uma organização supraestatal. Também nesses Campos se instituiu um mecanismo de diferenciação entre os subcidadãos e os supracidadãos, em benefício daqueles que migram para integrar programas de auxílio humanitário ${ }^{50}$.

Até mesmo o termo "refúgio" é excludente e sinaliza para uma limitação do acesso a vida pública. Dessa forma, como ressaltou Arendt, "primeiramente, nós não gostamos que nos chamem de 'refugiados'. Nós nos batizamos de 'novos chegados' ou 'imigrantes'"'51. Até o presente, o termo refugiado evocava a ideia de um indivíduo que havia sido constrangido a buscar refúgio motivado por um ato ou uma opinião política." Ainda hoje, os refugiados não se beneficiaram da difusão das normas internacionais de Direitos Humanos que, por exemplo, avançaram nas últimas décadas no que tange à extensão de direitos civis e sociais a migrantes, estrangeiros e naturalizados.

Os movimentos migratórios transnacionais questionam a tríade "estado-povoterritório", originando as chamadas "jurisdições sobrepostas"52. Essa sobreposição de Sistemas Jurídicos é originada pelas redes globalizadas de transporte, comunicação e serviços bancários internacionais, os quais demandam trabalhadores hóspedes, sazonais e/ou cidadãos com múltipla cidadania. A a migração não é mais apenas um instrumento de socialização, entendida como imersão total na nova cultura. Inclusive, países como Índia, China e Turquia incentivam "políticas de deslocamento" dos nacionais para melhorar a posição dos países de origem no fluxo global de capital, mantendo, entretanto, a ideia de fidelidade à "pátria-mãe".

Portanto, as migrações levam a uma "pluralização de fidelidades"53, possibilitando tanto que o centro flua para a periferia quanto que a periferia flua para o centro.

50 HYNDMANN, Jennifer. Managing Displacement: Refugees and the Politics of Humanitarism, Coleção Borderline, volume 16. Minnesota: University of Minnesota Press, 2000, p.31.

${ }^{51}$ ARENDT apud SCHIO, Sônia Maria. Kant e Arendt: os refugiados e o cosmopolitismo. In: ARALDI, Clademir Luís (org.); VALEIRÃO, Kelin (org.). Os herdeiros de Nietzsche: Foucault, Agamben e Deleuze. Pelotas: NEPFil online, 2016, p.247.

52 BENHABIB, Seyla. O declínio da soberania ou a emergência de normas cosmopolitas? Repensando a cidadania em tempos voláteis. p.28.

53 BENHABIB, Seyla. O declínio da soberania ou a emergência de normas cosmopolitas? Repensando a cidadania em tempos voláteis. p.29. 
BENEDETTI, Eduardo Jose Bordignon; SCHIO, Sônia Maria. A "mentalidade alargada" e os migrantes: reflexões a partir do pensamento político de Arendt. Revista Eletrônica Direito e Política, Programa de Pós-Graduação Stricto Sensu em Ciência Jurídica da UNIVALI, Itajaí, v.14, n.2, 20 quadrimestre de 2019. Disponível em: www.univali.br/direitoepolitica - ISSN 1980-7791

Dessa forma, as migrações, motivo de "intensos conflitos por recursos assim como por identidades" 54 , ensejam atualmente diversas reações dos Estados: alguns, para afirmar a sua soberania, militarizam e criminalizam os movimentos migratórios, outros defendem medidas restrita a um acolhimento humanitário ou, de maneira mais profunda, afirmam a necessidade de mudanças nos padrões de aculturação e de socialização. É crescente o número de migrantes que vivem em jurisdições múltiplas. Por isso, o conceito de cidadania deve ser entendido menos como filiação nacional e mais como cidadania de residência, em uma perspectiva que favoreça tanto os laços com as instituições locais quanto com as transnacionais.

Segundo o sociólogo John Urry ${ }^{55}$, a cidadania comporta diversas práticas, entre elas a "cidadania cultural" (que envolve o direito de todos os grupos sociais étnicos, sexuais, etários - de participação cultural completa dentro de sua sociedade), "cidadania ecológica" (os direitos e as responsabilidades do cidadão em relação à Terra) e a "cidadania de mobilidade" (direitos e responsabilidades de visitantes a outros lugares e outras culturas). Essas diversas práticas de cidadania, tal como as situações de sujeitos que vivem sob tutela de diversas jurisdições, atualizam o "direito a ter direitos" de Arendt, tanto em uma dimensão ontológica - o fato de pertencer à humanidade garante ao indivíduo o direito a ter direitos quanto em uma dimensão política - a existência de uma tutela internacional que garanta a efetividade desses direitos ${ }^{56}$.

A concepção de "direito a ter direitos", "ou o direito de cada indivíduo pertencer à humanidade, [que] deve ser garantido pela própria humanidade" 57 , permite refletir acerca das diversas dimensões espaço-temporais presentes na realidade da cidadania transnacional. Nesse aspecto, os Estados, na maioria das vezes, centram as suas preocupações no controle da movimentação de pessoas em suas

\footnotetext{
${ }^{54}$ BENHABIB, Seyla. O declínio da soberania ou a emergência de normas cosmopolitas? Repensando a cidadania em tempos voláteis. p.29.

55 URRY, John. Globalisation and Citizenship. World Congress of Sociology, Montreal, July 1998. Disponível em: http://www.lancaster.ac.uk/fass/resources/sociology-online-papers/papers/urryglobalisation-and-citizenship.pdf. Acesso em: 13.Fevereiro.2019.

56 LAFER, Celso. A reconstrução dos Direitos Humanos: um diálogo com o pensamento de Hannah Arendt. p.146.

${ }^{57}$ ARENDT, Hannah. As Origens do Totalitarismo. p.332.
} 
BENEDETTI, Eduardo Jose Bordignon; SCHIO, Sônia Maria. A "mentalidade alargada" e os migrantes: reflexões a partir do pensamento político de Arendt. Revista Eletrônica Direito e Política, Programa de Pós-Graduação Stricto Sensu em Ciência Jurídica da UNIVALI, Itajaí, v.14, n.2, 20 quadrimestre de 2019. Disponível em: www.univali.br/direitoepolitica - ISSN 1980-7791

fronteiras, sendo que as respostas ou são relegadas aos organismos internacionais ou consistem em estratégias de militarização crescente, que tratam das migrações unicamente como questão de segurança nacional ou, em casos extremos, como uma situação de acolhimento emergencial ${ }^{58}$.

Enfim, a extensão dos direitos civis e sociais para novas formas de cidadania, pensadas não mais a partir do pertencimento nacional e do enraizamento em uma comunidade cultural motiva "a ascensão do ativismo político por parte dos nãonacionais, pós-nacionais e ex-colonizados"59. Essa perspectiva de ativismo relaciona-se com o conceito de poder de Arendt. Ela não compartilha com a ideia de "poder" como uma forma de domínio de um sujeito sobre outro, seja pela força, pela violência ou até pela lei e, portanto, desenvolve um conceito de poder pensado a partir do agir conjunto do seres humanos. O poder é a

habilidade humana de não apenas agir, mas de agir em uníssono, em comum acordo. O poder jamais é propriedade de um indivíduo; pertence a um grupo e existe apenas enquanto o grupo se mantiver unido. Quando dizemos que alguém está 'no poder' estamos na realidade nos referindo ao fato de encontrar-se esta pessoa investida de poder, por um certo número de pessoas, para atuar em seu nome ${ }^{60}$.

É o poder gerado pela ação conjunta dos indivíduos que preserva a Política. Nesse sentido, as organizações da sociedade civil, que abrangem diversas práticas de cidadania (conforme elaborado por Urry), desempenham um papel importante na inclusão de temáticas negligenciadas relativas aos migrantes.

Nesse cenário, as demandas de direitos humanos baseiam-se não apenas em seu caráter normativo, mas também na atualização de seus sentidos e possibilidades. Benhabib (2012, p. 40-41) chama esse processo de "iterações democráticas", destacando tratar-se de "processos complexos de argumentação pública, deliberação e troca pelas quais reivindicações de direitos e princípios universalistas

\footnotetext{
58 Por exemplo, esse tem sido o enfoque da chamada "Operação Acolhida", criada em 2018, com a participação de diversas agências do governo federal, agências internacionais e organizações nãogovernamentais para acolhimento dos migrantes venezuelanos que chegam ao Brasil.

59 BENHABIB, Seyla. O declínio da soberania ou a emergência de normas cosmopolitas? Repensando a cidadania em tempos voláteis. p.39.

60 ARENDT, Hannah. A condição humana. p.24.
} 
BENEDETTI, Eduardo Jose Bordignon; SCHIO, Sônia Maria. A "mentalidade alargada" e os migrantes: reflexões a partir do pensamento político de Arendt. Revista Eletrônica Direito e Política, Programa de Pós-Graduação Stricto Sensu em Ciência Jurídica da UNIVALI, Itajaí, v.14, n.2, 20 quadrimestre de 2019. Disponível em: www.univali.br/direitoepolitica - ISSN 1980-7791

são contestados e contextualizados, invocados e revogados, postulados e posicionados"61. Ademais, são também "processos linguísticos, legais, culturais e políticos de repetição-em-transformação, invocações que são também revogações. São processos de legitimação e não de justificação"62. O conceito de mentalidade aralgada, tal como apropriado por Arendt a partir da estética kantiana, é importante também para o desenvolvimento desse argumento por Benhabib porque permite contextualizar o universal, de modo que relacione-se com o particular ${ }^{63}$.

As iterações, que ocorrem tanto em órgãos públicos quanto em associações da sociedade civil ou na mídia, são caracterizadas pela repetição; isto é, são processos nos quais agentes "falam em nome de" (e consequentemente repetem) os direitos humanos, a identidade da comunidade política, e as identidades culturais. Entretanto, quando assim o fazem, acabam por alterar o seu conteúdo. Dessa forma, o referencial antecedente é reposto e ressignificado pelas referencias subsequentes. Agindo em prol do mundo comum, as coletividades, reinterpretam continuamente certas normas e princípios a que estão vinculadas demonstrando serem elas mesmas sujeito e autoras das leis. Benhabib ${ }^{64}$ afirma ainda que as iterações são processos jurisgenerativos (termo empregado originalmente por Michelman de Robert Cover): são capazes de gerar resultados que valem como Direito, no sentido de dignidade de respeito, e não apenas por sua legitimidade formal.

Esses processos comunicativos e linguísticos em que a noção de direitos humanos é evocada para o estabelecimento de uma cidadania transnacional, retomam ação política, como teoriazada por Arendt: são irresistíveis (porque são inescapavael, inevitáveis), imprevisíveis (são inícios, permitem o surgimento do novo) e ilimitados (não obedecem as barreiras e fronteiras). Assim, quando as políticas

${ }^{61}$ BENHABIB, Seyla. O declínio da soberania ou a emergência de normas cosmopolitas? Repensando a cidadania em tempos voláteis. p.40.

62 BENHABIB, Seyla. O declínio da soberania ou a emergência de normas cosmopolitas? Repensando a cidadania em tempos voláteis. p.41.

63 BENHABIB, Seyla. Situating the self. Gender, community and postmodernism in contemporary ethics. New York: Routledge, 1992, p.134 e seguintes.

64 BENHABIB, Seyla. O declínio da soberania ou a emergência de normas cosmopolitas? Repensando a cidadania em tempos voláteis.p.42 
BENEDETTI, Eduardo Jose Bordignon; SCHIO, Sônia Maria. A "mentalidade alargada" e os migrantes: reflexões a partir do pensamento político de Arendt. Revista Eletrônica Direito e Política, Programa de Pós-Graduação Stricto Sensu em Ciência Jurídica da UNIVALI, Itajaí, v.14, n.2, 20 quadrimestre de 2019. Disponível em: www.univali.br/direitoepolitica - ISSN 1980-7791

de tratamento hostil ao imigrante cedem lugar à esperança e ao amor mundi65, as práticas de cidadania transnacional podem também estabelecer, em certa medida, um limite ao predomínio do "homem de massa" - aquele que, mesmo considerando-se no pleno exercício da cidadania, perdeu a dimensão do mundo comum e vive ou "em uma separação desesperadamente solitária" ou "comprimido em uma massa"66.

\subsection{A mentalidade alargadas e as reinvindicações de direitos}

A Política pode "humanizar o mundo através do contínuo e incessante diálogo"67. A comunicabilidade, por sua vez, depende da mentalidade alargada. A imaginação livre, por relacionar-se às capacidades do espírito humano (pensar, querer e julgar) é mais do que pensar a situação por diversas perspectivas. Arendt afirma que "quanto maior o alcance, quanto mais amplo é o domínio em que o indivíduo esclarecido é capaz de mover-se de um ponto de vista a outro, mais 'geral' será esse pensamento"68. Exercitar o "pensar alargado", é uma atividade que se relaciona com a "sociabilidade", porque trata da satisfação advinda de considerar a perspectiva dos outros nos domínios éticos e políticos.

Em Arendt, a "perda da tradição" relaciona-se com a ruptura, a nível do espírito, em que aquilo que foi não pode ser critério para avaliar o que virá. Considerando a influência de Kant no pensamento arendtiano, percebe-se que, diante da perda da tradição, é necessária a utilização do julgamento estético reflexivo. Esse juízo, que julga um particular "para o qual o geral deve ser encontrado" (ao contrário do juízo determinante, que subjuga o particular sob uma regra geral), permite a

\footnotetext{
65 O conceito de amor mundi significa que o ser humano deve "sentir-se em casa no mundo", enfatizando o cuidado com a sua perpetuação. Conforme Arendt: "Em última análise, o mundo humano é sempre o produto do amor mundi do ser humano, um artifício humano cuja imortalidade potencial está sempre sujeita à mortalidade daqueles que o ergueram e à natalidade daqueles que chegam para viver nele." ARENDT, Hannah. A promessa da Política. Tradução de Pedro Jorgensen Junior. Rio de Janeiro: Difel, 2008, p.204.

66 ARENDT, Hannah. Entre o Passado e o Futuro. Tradução Mauro W. Barbosa. São Paulo: Nova Perspectiva, 1992, p.126.

67 ARENDT, Hannah. Homens em tempos sombrios. Tradução de Denise Bottmann. São Paulo: Companhia das Letras, 1987, p.42.

68 ARENDT, Hannah. Lições sobre a filosofia política de Kant. p.71.
} 
BENEDETTI, Eduardo Jose Bordignon; SCHIO, Sônia Maria. A "mentalidade alargada" e os migrantes: reflexões a partir do pensamento político de Arendt. Revista Eletrônica Direito e Política, Programa de Pós-Graduação Stricto Sensu em Ciência Jurídica da UNIVALI, Itajaí, v.14, n.2, $2^{\circ}$ quadrimestre de 2019. Disponível em: www.univali.br/direitoepolitica - ISSN 1980-7791

eclosão do novo, coadunando-se com a perspectiva de espontaneidade e contingência com que Arendt caracteriza a política. Segundo Arendt, o ser humano pode ser caracterizado como um "iniciador":

Nessa mesma via, poder-se-ia responder à pergunta sobre os motivos pelos quais nos inquietamos com questões tão obviamente irrespondíveis - o mundo, ou o universo, têm um começo, ou são, como Deus, de eternidade a eternidade? apontando para o fato de que é da nossa própria natureza sermos iniciadores e, por conseguinte, de constituirmos começos durante toda a nossa vida69.

Pela atividade do juízo estético reflexionante, os sujeitos permanecem abertos para os "novos começos". A partir dessa perspectiva, é possível analisar filosoficamente as reivindicações de direitos, que inauguram entendimentos radicalmente novos de igualdade e liberdade. Os conflitos de imigrantes e as crises de terrorismo, demonstram as fragilidades dos direitos humanos, se considerados como "universais" por um enfoque formal ou simplesmente enquanto baseados em um juízo determinante. É, portanto, imprescindível a atenção às situações específicas - ao que os sujeitos "sentem" enquanto um corpo em um espaço (ou excluídos deste) -, o que pode ocorrer a partir da "visita" ao ponto de vista do outro, de um pensar "alargado". Dessa forma, o "direito a ter direitos" é uma garantia para que, em relação aos sujeitos da política, todos possam ser "iniciadores".

Todavia, em uma perspectiva arendtiana, essas reinvindicações não podem ser analisadas em uma concepção puramente relativistas, porque elas demandam um acordo universal - isto é, necessitam da comunicabilidade, desse "sentido extra" que Kant denominou sensus communis. Em relação às atividades do espírito, é a imaginação, em jogo livre com o entendimento, que torna possível presentificar o que está ausente, permitindo novas perspectivas, outros desenvolvimentos para questões controversas e também conexões entre questões aparentemente distintas.

${ }^{69}$ ARENDT, Hannah. Lições sobre a filosofia política de Kant. P.20 
BENEDETTI, Eduardo Jose Bordignon; SCHIO, Sônia Maria. A "mentalidade alargada" e os migrantes: reflexões a partir do pensamento político de Arendt. Revista Eletrônica Direito e Política, Programa de Pós-Graduação Stricto Sensu em Ciência Jurídica da UNIVALI, Itajaí, v.14, n.2, 20 quadrimestre de 2019. Disponível em: www.univali.br/direitoepolitica - ISSN 1980-7791

Diferentemente de quando se trata de conhecimento, em que uma verdade científica possui validade objetiva, na política a persuasão é imprescindível. Além de "pensar por si mesmo", é necessário um "pensar alargado". Essa maneira de pensar pode ser exemplificada em situações cotidianas, em que a "transposição para o lugar do outro", faz com o que o sujeito modifique o seu pensamento e a sua ação. Em se tratando de direitos, a faculdade que todos os humanos possuem (e que permite "levar em conta o modo de representação de todas as outras pessoas"), requer que, entre essas "outras pessoas", seja representada também a perspectiva daqueles sujeitos que passam as bordas (imigrantes), ou sequer pertencem determinada ordem política (refugiados e apátridas, por exemplo). Esse pensar alargado transcende as limitações do "acolhimento"; trata-se de colocar-se no lugar de quem chega, daquele que não tem lugar na terra, incluindo esse ponto de vista no jogo das perspectivas possíveis. Dessa forma, pode-se estabelecer uma mediação, uma contextualização, entre a universalidade dos direitos humanos e as especificidades espaço-temporais.

\section{CONSIDERAÇÕES FINAIS}

Atualmente, os "paradoxos" do "direito a ter direitos" são aperfeiçoados por aqueles que exercitam seus direitos de participação ${ }^{70}$, superando as limitações da soberania estatal. Ademais, a temática da migração é um assunto em constante destaque nos meios de comunicação, de maneira que as entidades da sociedade civil dedicadas a essa temática reúnem indivíduos, muitas vezes movidos por aquilo que denominam de "sentimento de injustiça". Nesses casos, as imagens e os relatos afetam a todos como uma "sensação", sendo, em realidade, efeito da "faculdade de julgar". Em outros termos, "daquilo que converte nosso sentimento [como sensação], em uma dada representação [não percepção] comunicável em geral, sem a mediação de um conceito"71. Essa sensação é expressa pelos

70 Por isso, Benhabib defende um "federalismo republicano", em que haja a "reagregação constitucionalmente estruturada dos criadores da soberania, em um conjunto de instituições interligadas, cada qual responsável por e devedora de prestação de contas perante a outra."

BENHABIB, Seyla. O declínio da soberania ou a emergência de normas cosmopolitas? Repensando a cidadania em tempos voláteis. p.39-40.

${ }^{71}$ ARENDT, Hannah. Lições sobre a filosofia política de Kant. p.92. 
BENEDETTI, Eduardo Jose Bordignon; SCHIO, Sônia Maria. A "mentalidade alargada" e os migrantes: reflexões a partir do pensamento político de Arendt. Revista Eletrônica Direito e Política, Programa de Pós-Graduação Stricto Sensu em Ciência Jurídica da UNIVALI, Itajaí, v.14, n.2, $2^{\circ}$ quadrimestre de 2019. Disponível em: www.univali.br/direitoepolitica - ISSN 1980-7791

indivíduos como um "sentimento de indignação", algo que escapa a um "conceito" ou aos preceitos normativos da ação moral. Essa "indignação diante da injustiça" chama a atenção para esse "outro", que não se encaixa tríade "estado-povoterritório".

Por outro lado, em uma sociedade da massa, parece que a presença ou a ausência desse "outro" é notada apenas quando atinge o fator econômico. Nesse ponto, é central a questão de como receber esse "outro", que exerce o seu "direito de visita". Os "novos chegados" não podem ser tratados como "parasitas", serem reduzidos a sua utilidade (mão de obra de barata, por exemplo) ou excluídos da vida comum (a recepção dos migrantes restrita a estratégias de interiorização, por exemplo). O entendimento comum dos homens, conforme Kant, "é o mínimo que se pode esperar de qualquer um que se pretenda ter o nome de homem." ${ }^{72}$ Para haver esse entendimento é necessária a responsabilidade pelo mundo comum (amor mundi).

O mundo comum é "aquilo que adentramos ao nascer e que deixamos para trás quando morremos"73. Apesar do sistema de nações sugerir um mundo fragmentado, o mundo comum é um mundo único, que deve ser preservado no presente para as gerações futuras. Enfim, a "leitura política da mentalidade alargada" retoma o pensamento arendtiano em sua valorização da política, que, marcada pela pluralidade, possibilita reflexões acerca do cosmopolitismo, não somente enquanto direito de visita, mas no sentido de preservar a possibilidade de irrupção do genuinamente novo; isto é, do sujeito que "nasce", sendo de um mundo que é anterior a ele, mas que deve estar preservado quando ele deixar de existir.

\section{REFERÊNCIA DAS FONTES CITADAS}

AGAMBEN, Giorgio. Homo Sacer. O Poder Soberano e a Vida Nua I. Tradução de Henrique Burigo. Belo Horizonte: Editora UFMG, 2002

\footnotetext{
72 Conforme citado por ARENDT, Hannah. Lições sobre a filosofia política de Kant. p.90

${ }^{73}$ ARENDT, Hannah. A condição humana. p.67.
} 
BENEDETTI, Eduardo Jose Bordignon; SCHIO, Sônia Maria. A "mentalidade alargada" e os migrantes: reflexões a partir do pensamento político de Arendt. Revista Eletrônica Direito e Política, Programa de Pós-Graduação Stricto Sensu em Ciência Jurídica da UNIVALI, Itajaí, v.14, n.2, $2^{\circ}$ quadrimestre de 2019. Disponível em: www.univali.br/direitoepolitica - ISSN 1980-7791

ARENDT, Hannah. Homens em tempos sombrios. Tradução de Denise Bottmann. São Paulo: Companhia das Letras, 1987.

As Origens do Totalitarismo. Tradução de Roberto Raposo. São Paulo: Companhia das Letras, 1989

Paulo: Nova Perspectiva, 1992

Entre o Passado e o Futuro. Tradução Mauro W. Barbosa. São

A dignidade da política. Tradução de Helena Martins. Rio de Janeiro: Relume Dumará, 1993.

Lições sobre a filosofia política de Kant. 2.ed.Tradução de André Duarte. Rio de Janeiro: Relume Dumará, 1994

A Vida do Espírito: o pensar, o querer, o julgar. Traduçaõ de Antonio Abranches, Augusto R de Almeida e Helena Martins. Rio de Janeiro: Relume Dumará, 2002

p.175-201, 2005.

- Trabalho, obra, ação. Cadernos de Ética e Filosofia Política. Tradução de Adriano Correia. Revisão de Theresa Calvet de Magalhães . São Paulo, volume 7, número 2, p.175-201, 2005.

A condição humana. Tradução de Roberto Raposo Rio de Janeiro: Forense Universitária, 2010.

A promessa da Política. Tradução de Pedro Jorgensen Junior. Rio de Janeiro: Difel, 2008

ASSY, Bethânia. A Moldura de uma Existência Cosmopolita: Cultivo de Sentimentos Públicos Uma Leitura Arendtiana. Direito e Práxis, Rio de Janeiro, volume 04, número 01, p.53-72, 2012.

Ética, responsabilidade e juízo em Hannah Arendt. São Paulo:

Perspectiva; São Paulo: Instituto Norberto Bobbio, 2015.

BEINER, Ronald. Hannah Arendt - sobre o Julgar. In: ARENDT, Hannah; BEINER, Ronald (org). Lições sobre a Filosofia Política de Kant. Rio de Janeiro: Relume Dumará, 1994.

BENHABIB, Seyla. Situating the self. Gender, community and postmodernism in contemporary ethics. New York: Routledge, 1992.

Littlefield, 1996.

. The Reluctant Modernity of Hannah Arendt. Oxford: Rowman \&

. BENHABIB, Seyla. O declínio da soberania ou a emergência de normas cosmopolitas? Repensando a cidadania em tempos voláteis. Tradução de João 
BENEDETTI, Eduardo Jose Bordignon; SCHIO, Sônia Maria. A "mentalidade alargada" e os migrantes: reflexões a partir do pensamento político de Arendt. Revista Eletrônica Direito e Política, Programa de Pós-Graduação Stricto Sensu em Ciência Jurídica da UNIVALI, Itajaí, v.14, n.2, $2^{\circ}$ quadrimestre de 2019. Disponível em: www.univali.br/direitoepolitica - ISSN 1980-7791

Carlos Bassani e Johanna Clarissa Beckert. Civitas. Porto Alegre, volume 12, número 1, p. 20-46, 2012.

DENAMAY, Sylvie Courtine. Hannah Arendt. Tradução de Ludovina Figueiredo. Lisboa: Piaget, 1994, P.404

DUARTE, André. A dimensão política da filosofia kantiana segundo Hannah Arendt. In: In: ARENDT, Hannah; BEINER, Ronald (org). Lições sobre a Filosofia Política de Kant. Rio de Janeiro: Relume Dumará, 1994

FALERO, Alfredo. Migración laboral: un desafío para la sociedad civil. Revista de Ciencias Sociales, 2002, volume XV, número 20, p. 50-62.

HYNDMANN, Jennifer. Managing Displacement: Refugees and the Politics of Humanitarism, Coleção Borderline, volume 16. Minnesota: University of Minnesota Press, 2000.

KANT, Immanuel. Crítica da Faculdade do Juízo. 3.ed. Tradução de Valério Rohden e António Marques. Rio de Janeiro: Forense Universitária, 2008.

LAFER, Celso. A reconstrução dos Direitos Humanos: um diálogo com o pensamento de Hannah Arendt. São Paulo: Companhia das Letras, 1988.

e Terra, 1979.

- Hannah Arendt: pensamento, persuasão, poder. Rio de Janeiro: Paz

ORLIE, Melissa. Living etically, acting politically. New York: Cornell University, 1997.

ROHDEN, Valério. Juízo e reflexão desde de um ponto de vista prático. O que nos faz pensar, Rio de Janeiro, volume 1, número 09, p. 40-53, 1995.

SCHIO, Sônia Maria. Hannah Arendt: a estética e a política (do juízo estético ao juízo político). Tese de doutorado, Porto Alegre: Universidade Federal do Rio Grande do Sul, 2008.

- Hannah Arendt: imaginação e juízo político. In: SIVIERO, Iltomar; ROSIN, Nilva (Org.). Hannah Arendt: diversas leituras. Passo Fundo: IFIBE, 2010, p. 45-60.

Alegre: Clarinete, 2012.

- Hannah Arendt: história e liberdade: da ação a reflexão. Porto

- Kant e Arendt: os refugiados e o cosmopolitismo. In: ARALDI, Clademir Luís (organização); VALEIRÃO, Kelin (organização). Os herdeiros de Nietzsche: Foucault, Agamben e Deleuze. Pelotas: NEPFil online, 2016, p.241252.

URRY, John. Globalisation and Citizenship. World Congress of Sociology, Montreal, July $1998 . \quad$ Disponível em: 
BENEDETTI, Eduardo Jose Bordignon; SCHIO, Sônia Maria. A "mentalidade alargada" e os migrantes: reflexões a partir do pensamento político de Arendt. Revista Eletrônica Direito e Política, Programa de Pós-Graduação Stricto Sensu em Ciência Jurídica da UNIVALI, Itajaí, v.14, n.2, $2^{\circ}$ quadrimestre de 2019. Disponível em: www.univali.br/direitoepolitica - ISSN 1980-7791

http://www.lancaster.ac.uk/fass/resources/sociology-online-papers/papers/urryglobalisation-and-citizenship.pdf. Acesso em: 19.Mar.2019.

RECEBIDO EM: 13/05/2019

APROVADO EM: 23/07/2019 